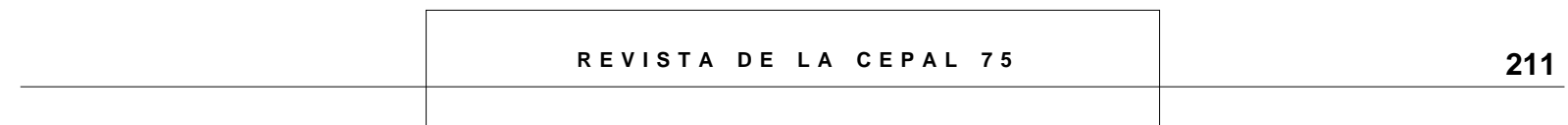

\title{
El comercio de los productos transgénicos: el estado del debate internacional
}

\section{María Angélica Larach}

División de Comercio

Internacional

e Integración,

CEPAL

mlarach@eclac.cl
Los productos transgénicos mezclan aspectos contradictorios.

La manipulación genética de cultivos permite desarrollar tanto productos con toxinas insecticidas, disminuyendo el uso de defensivos agrícolas que pueden dañar el medio ambiente, como alimentos con propiedades vitamínicas y proteicas, que pueden mejorar los indicadores sociales en los países en desarrollo. Por otra parte, se han abierto interrogantes acerca de los posibles efectos de los productos transgénicos sobre la bioseguridad y la biodiversidad y de los riesgos de su consumo. Los diversos actores que intervienen en el debate acerca de esos productos mantienen posiciones dispares en lo que se refiere a su comercialización. El proceso de negociación y posterior aprobación del Protocolo de Bioseguridad, así como las contiendas acerca de la aceptación del principio precautorio o de las normas de la Organización Mundial de Comercio (OMC) para restringir la producción y comercialización de los transgénicos, mostraron grandes divergencias entre gobiernos. 


\section{I}

\section{Introducción}

\section{Antecedentes}

Desde hace unas décadas se están llevando a cabo nuevas investigaciones biotecnológicas con aplicaciones económicas. El rápido progreso de la biotecnología ("la revolución genética") tiende a ser comparado con el de la "revolución verde" de los decenios de 1960 y 1970. La nueva biotecnolología ${ }^{1}$ tiene a su vez relación directa con la bioseguridad y la biodiversidad, ambas herramientas importantes para que un país pueda lograr un desarrollo agrícola económico y eficiente.

Las técnicas de la ingeniería genética desempeñan un papel fundamental en el avance de la biotecnología agrícola e inciden particularmente en los insumos que se utilizan en la agricultura y en la producción de alimentos. La manipulación de los genes existentes permite a las empresas agroindustriales desarrollar nuevas variedades de cultivos y de alimentos procesados, con menor uso de insumos energéticos o químicos.

El uso de la biotecnología agrícola genera grandes expectativas, y también incertidumbres ante potenciales riesgos. Preocupan sus posibles repercusiones en la salud humana y en el medio ambiente. Aun cuando hasta la fecha no existen evidencias de que la biotecnología afecte la inocuidad de los alimentos, persiste en la sociedad la desconfianza ante el consumo de sus derivados.

El Convenio de la Diversidad Biológica (CDB) define la biotecnología como "toda aplicación tecnológica que utilice sistemas biológicos y organismos vivos o sus derivados para la creación o modificación de productos o procesos para usos específicos". Esta definición abarca una gama de técnicas usadas en la agricultura y en la industria de alimentos, como las técnicas $\mathrm{ADN}^{2}$ y reproductivas, y la manipulación y transferencia de genes. Con su aplicación es posible modificar los alimentos en forma más rápida y mejor dirigida.

Las técnicas de la ingeniería genética permiten alterar las características heredadas de los organismos

\footnotetext{
1 En adelante, se entenderá por biotecnología la biotecnología moderna o nueva biotecnología.

2 Cadena de ácidos nucleicos, donde se guarda el material genético que rige el desarrollo de células y organismos.
}

vivos: de un individuo, animal o planta. Los genes individuales son sacados del genoma de un organismo e introducidos en el genoma de otro, de tal modo que al mover los genes se mueven también sus rasgos y características y se producen nuevas sustancias o nuevas funciones. El organismo resultante tiene una nueva combinación de genes que no se encuentra en la naturaleza y que no puede lograrse por mecanismos naturales. Su empleo permite aumentar o bloquear la cantidad de proteínas producidas por un organismo en aquellos que no las producen, o que si lo hacen, se desea anular (OCDE, 1999a).

Una segunda aplicación biotecnológica es el empleo de las técnicas recombinantes ADN. Los científicos pueden aislar los genes de distintos organismos, de distintas especies o de una misma especie, fraccionarlos, unirlos, y agregar o trasladar, en forma voluntaria y consciente, el material genético entre las distintas variedades. Esta técnica tiene una capacidad precisa de intervención. Como el ADN es parte del núcleo de las células, la información genética se desplaza entre organismos no relacionados para producir uno nuevo. Así, con la tecnología existente la información hereditaria puede traspasar las barreras de la especie (OCDE, 1999a y 1999b; Grace, 1997).

Con la ruptura de las barreras biológicas y el cruce entre especies se obtienen alimentos u organismos transgénicos. El nuevo organismo con el atributo de aquellas características genéticas deseadas es una variedad de cultivo idéntica a la tradicional, pero que incorpora nueva información genética.

\section{Los temas y los actores del debate internacio- nal}

\section{a) Los temas}

Las aplicaciones biotecnológicas proyectan contribuir a satisfacer las crecientes necesidades alimentarias de la población mundial. Al mismo tiempo, los científicos y empresarios advierten que el avance de la ciencia, además de ofrecer beneficios a la sociedad, plantea riesgos y desafíos de orden ético, ambiental y sanitario.

Eticos, pues es en los territorios de las comunidades indígenas de algunos países en desarrollo don- 
de se encuentran la propiedad y los conocimientos de los recursos genéticos. Estos países y comunidades no son considerados en el reparto de los beneficios por las empresas que detentan la tecnología. El empleo de la biotecnología no puede mirarse solamente desde el punto de vista científico, ya que al intervenir se producen combinaciones genéticas que podrían transgredir las leyes de la naturaleza.

Ambientales, pues las aplicaciones biotecnológicas agrícolas plantean posibles riesgos de reducir la biodiversidad y de afectar el equilibrio biológico. Los cultivos pueden llevarse a una homogeneidad desde el punto de vista genético de plantas y organismos. Al extender el área dedicada a una sola siembra se reduce la variedad de cultivos y se contribuye a la pérdida de la diversidad genética, especialmente en las zonas rurales. Asimismo, se puede presentar el riesgo de desarrollar hierbas silvestres resistentes a insecticidas o a enfermedades que puedan desequilibrar el ecosistema.

Por último, el temor de que el consumo de alimentos transgénicos provoque riesgos para la salud surge por no contar con respaldo científico razonable que demuestre que estos alimentos son inocuos. Se trata de riesgos como el de transferencia de toxinas o de compuestos alergénicos de una especie a otra, creación de nuevas toxinas o aparición de reacciones alérgicas insospechadas. Este es uno de los problemas latentes en el debate actual. El escaso tiempo que ha transcurrido desde el lanzamiento de este tipo de productos lo hace de difícil manejo, por la insuficiente evidencia con que se cuenta para determinar si los alimentos transgénicos son, o no son, un peligro para la salud humana.

Al utilizar organismos transgénicos en la producción agrícola se comprueban mejoras de algunas características originales. Hay mayor resistencia a ciertos pesticidas o herbicidas y a enfermedades o plagas (virus, hongos, insectos y parásitos). La producción se adapta mejor a condiciones medioambientales — como heladas, sequías y suelos- que con las técnicas tradicionales no se destacaban como favorables; es mayor el contenido de nutrientes y se incorpora mayor contenido vitamínico, en minerales o proteínas; se reduce el contenido de grasa; mejora el sabor, color o textura de los alimentos, y se facilita su elaboración y almacenamiento.

Un aporte de las modificaciones genéticas es el de introducir elementos destinados a disminuir el riesgo de infección y reducir el uso de sustancias químicas para el control de plagas. Sin embargo, algunos señalan que esta resistencia actúa también como ame- naza a la diversidad biológica, porque los agricultores tienden a cultivar variedades de plantas genéticamente uniformes, o porque se afecta la conservación y/o se reduce la utilización de cultivos tradicionales.

Otro resultado desfavorable es el desprendimiento de microorganismos en la tierra que pueden generar cambios bioquímicos y afectar el equilibrio del ecosistema. A ello se suma el impacto negativo de las cosechas transgénicas en la conservación de cultivos laterales tradicionales, al polinizarlos con elementos modificados genéticamente y traspasarlos a nuevas generaciones de cultivos. Por otra parte, la biotecnología ha desarrollado nuevos pesticidas y plaguicidas más potentes que destruyen las malezas o plagas y evitan que merme la productividad de los cultivos, pero puede poner en peligro otras plantas deseables para conservar la diversidad biológica (Brañes y Rey, 1999).

Igualmente, el cultivo de transgénicos puede provocar cambios socioeconómicos en países menos desarrollados, desplazando mano de obra de una de sus principales actividades económicas. En esos países, una labor importante es el cultivo de alimentos básicos como el maíz; un desplazamiento de la mano de obra ocupada en él puede arriesgar la fuente de subsistencia de una parte importante de la población.

\section{b) Los actores}

En el debate internacional participan gobiernos, empresas biotecnológicas, científicos, organizaciones no gubernamentales, agricultores, consumidores y ambientalistas; algunos tienen una posición más crítica que otros ante la aplicación de las nuevas técnicas. Estos grupos no son homogéneos, y presentan diferencias entre ellos y dentro de un mismo grupo.

Dos principales corrientes, opuestas en sus argumentos, aparecen en los debates respecto al uso de la biotecnología. Una está constituida por partidarios de la nueva biotecnología y la integran especialmente productores y distribuidores; la otra es de rechazo y la sostienen principalmente consumidores y ambientalistas.

Los partidarios del avance de la industria biotecnológica destacan que la mayor oferta productiva permitiría a los consumidores obtener los alimentos a precios más bajos debido a los menores costos de producción, el menor uso de insumos productivos y de elementos químicos, los mayores rendimientos y la oferta de técnicas de producción más amigables con el medio ambiente. La aplicación de estas técnicas en sus cultivos ha favorecido a éstos con una mayor resistencia a plagas, enfermedades o condiciones ambientales adversas. 
La industria biotecnológica es manejada principalmente por un grupo reducido de empresas trasnacionales, localizadas de preferencia en países industrializados. Estas empresas desarrollan y comercializan productos y procedimientos y se preocupan de generar eficiencia en la producción y de lograr utilidades. Los elevados gastos que requiere la innovación biotecnológica hacen que el mercado mundial de semillas, fertilizantes y plaguicidas se concentre en unas pocas empresas. Estas destacan en su campaña a favor de los productos transgénicos las pequeñas cantidades de estos insumos requeridas en la producción. Sin embargo, las trasnacionales no publican que son ellas mismas las mayores productoras de tales insumos químicos agrícolas: controlan el $60 \%$ del mercado de pesticidas y el $100 \%$ del mercado de semillas transgénicas.

Los distribuidores también ganan con el avance de la biotecnología, pues los alimentos transgénicos perecibles pueden almacenarse por mayor tiempo sin que se altere su condición.

Los científicos no tienen una posición única. Están divididos entre los que defienden la inocuidad de los alimentos transgénicos, pues hasta el momento éstos no han causado grandes accidentes en la salud ni en el medio ambiente, y los que consideran que ellos presentan riesgos potenciales. Dado lo sensible que es la opinión pública al tema biotecnológico, es preciso que los científicos acrecienten sus esfuerzos de investigación para lograr una evaluación objetiva e imparcial de sus efectos.

La comunidad científica que apoya la biotecnología considera un avance el uso de las nuevas técnicas genéticas que, bien utilizadas, podrían beneficiar a los países al mejorar los rendimientos de los cultivos, ahorrar gastos en insumos o perfeccionar la producción mediante adiciones de elementos nutritivos en los alimentos. Por otra parte, estiman que facilitando el acceso a los mercados se ayudaría a los países productores en desarrollo a disminuir su dependencia de la importación de alimentos básicos, lo que les permitiría enfrentar hambrunas en zonas deprimidas.

Los consumidores tampoco están muy organizados, pero, a diferencia de los científicos, disponen de información confusa sobre los riesgos y beneficios para la salud que aportan los alimentos transgénicos. La información que reciben es incompleta, pues las empresas productoras no siempre publican el origen transgénico de los productos, lo que aumenta el grado de incertidumbre. Consideran que tienen el derecho a acceder a alimentos inocuos y de calidad y de conocer qué insumos se incorporaron en su producción. Reclaman transparencia, educación e información veraz, adecuada y oportuna de los beneficios o riesgos para la salud. No siempre creen que los resultados de los estudios científicos son veraces. Son muy reacios a aceptar productos agrícolas que dañan el medio ambiente. Argumentan que hay nula regulación o reglas inapropiadas. Y reclaman mayor participación de los gobiernos, responsables de organizar la producción y comercialización de los nuevos productos.

Los avances biotecnológicos contribuyen a crear nuevos alimentos de origen agrícola y agroindustrial. Puesto que ellos están dirigidos a la sociedad, se debiera prestar mayor atención a los reclamos de los consumidores. La sociedad exige que los gobiernos detecten y evalúen los posibles riesgos para la salud antes de comercializar el alimento transgénico.

Los ambientalistas generalmente se oponen a la producción de estos alimentos porque consideran que imponen riesgos al medio ambiente y a la biodiversidad y que falta evaluar eventuales peligros. A este grupo se suman las organizaciones no gubernamentales, participantes activos en estos debates.

Los debates apuntan a la necesidad de realizar estudios más acuciosos sobre los efectos que la aplicación de las técnicas de la ingeniería genética pueda tener en la salud humana, en el medio ambiente y en la agricultura, y ponen de relieve que la tarea es cómo producir más, otorgando reales beneficios a la sociedad.

El examen de los efectos de incorporar las aplicaciones biotecnológicas al medio agrícola se ha centrado principalmente en los países desarrollados, particularmente en los Estados Unidos y en países de Europa occidental. No obstante, las diferentes interpretaciones sobre la inocuidad de los productos transgénicos que surgen en el mundo desarrollado hacen aflorar inquietudes que repercuten anticipadamente en los países en desarrollo. Al aparecer los primeros productos transgénicos, algunos gobiernos se han preocupado más que otros de la bioseguridad, regulando los cultivos transgénicos en los campos experimentales y aportando antecedentes que aseguren la carencia de riesgo antes de que el producto modificado se lance al mercado. 


\section{II}

\section{La producción y el comercio de alimentos transgénicos}

\section{Producción mundial}

La sorprendente tasa de crecimiento de la superficie plantada con cultivos transgénicos coloca a los productores agrícolas frente a un enorme desafío. Según James (2000), la superficie mundial plantada con tales cultivos aumentó de 1.7 millón a cerca de 40 millones de hectáreas entre 1996 y 1999. Al aumento de 44\% entre 1998 y 1999 contribuyeron cuatro países industrializados y cuatro en desarrollo. ${ }^{3}$ La superficie con cultivos transgénicos en los Estados Unidos alcanzó a 29 millones de hectáreas en 1999, cerca de 80\% de la superficie dedicada a estos productos en el mundo (cuadro 1).

En 2000, esa última superficie aumentó, pero más lentamente. El crecimiento de $11 \%$ sobre el año anterior equivale a un aumento de 4.3 millones de hectáreas, de las cuales 3.6 millones corresponden a países en desarrollo (84\% del área total). El 0.7 millón de hectárea restante corresponde a países industrializados (16\%). En el período 1996-2000, el área plantada au-

\begin{tabular}{|c|c|c|c|c|}
\hline \multirow[t]{2}{*}{ CUADRO 1} & \multicolumn{4}{|c|}{$\begin{array}{l}\text { Algunos países: Superficie de cultivos } \\
\text { transgénicos, por países, }{ }^{\mathrm{a}} \text { 1997-2000 } \\
\text { (Millones de hectáreas) }\end{array}$} \\
\hline & 1997 & 1999 & 2000 & $\begin{array}{c}2000 / 1999 \\
(\%)\end{array}$ \\
\hline Estados Unidos & 8.1 & 28.7 & 30.3 & 6 \\
\hline Argentina & 1.4 & 6.7 & 10.0 & 49 \\
\hline Canadá & 1.3 & 4.0 & 3.0 & -25 \\
\hline Australia & 0.1 & 0.1 & 0.2 & 100 \\
\hline México & 0.1 & 0.1 & $<0.1$ & 0.0 \\
\hline Europa & $\ldots$ & $\ldots$ & $\ldots$ & $\ldots$ \\
\hline Total & 11.0 & 39.9 & 44.2 & 11.0 \\
\hline
\end{tabular}

Fuentes: Agrodigital, 11-05-99, el Centro Bioinfo, http:// www.biotechknowledge.com; referencia 2781 .

a Se excluye China. Su inclusión aumenta el área total en 1997 a 12.8 millones de hectáreas.

\footnotetext{
${ }^{3}$ Sudáfrica, Argentina, Australia, Canadá, España, Estados Unidos, Francia y México.
}

mentó 25 veces y el número de países con cultivos transgénicos subió de 6 a 13. Hoy, estos cultivos se han extendido a Australia, China, India, Malasia y Tailandia.

A Estados Unidos, Canadá y Argentina correspondía en 2000 un $98 \%$ de la superficie total plantada con semillas transgénicas. En ese año el 100\% del área total con cultivos transgénicos correspondió a soja, maíz, algodón y canola. De los 273 millones de hectáreas dedicadas a estos cuatro productos en el mundo, un $16 \%$ correspondió a cultivos modificados (cuadro 2).

En 2000, la soja modificada cubrió 26 millones de hectáreas mundiales tras un aumento de $19 \%$ sobre el año anterior, llegando así al 58\% de la superficie cultivada con semillas transgénicas. De los 72 millones de hectáreas de soja en el mundo, 34\% correspondía a la modificada.

Entre 1999 y 2000 la superficie mundial cultivada con maíz modificado disminuyó 11.1 millones de hectáreas a 10.3 millones De los 140 millones de hectáreas dedicadas a maíz, 7\% corresponde a cultivo transgénico. Las disminuciones en Estados Unidos y Canadá se compensaron con aumentos en Argentina y Sudáfrica. En 2000, la Agencia de Protección Ambiental (EPA) de los Estados Unidos advirtió a sus agricultores de maíz modificado que debían reservar entre un $20 \%$ y $50 \%$ de su área de cultivo para productos tradicionales, para ayudar así a detener el aumento de cultivos transgénicos.

CUADRO 2

Mundo: Superficie con cultivos transgénicos, 1996 a 2000 (Millones de hectáreas)

\begin{tabular}{lrrrrrr}
\hline Cultivos & 1996 & $\%$ & 1999 & $\%$ & 2000 & $\%$ \\
\hline Tomate & 0.1 & 4 & $\ldots$ & $\ldots$ & $\ldots$ & $\ldots$ \\
Papa & $\ldots$ & $\ldots$ & 0.1 & $\ldots$ & $\ldots$ & $\ldots$ \\
Soja & 0.5 & 18 & 21.6 & 54 & 25.8 & 58 \\
Maíz & 0.3 & 10 & 11.1 & 28 & 10.3 & 23 \\
Tabaco & 1 & 35 & $\ldots$ & $\ldots$ & $\ldots$ & $\ldots$ \\
Algodón & 0.8 & 28 & 3.7 & 9 & 5.3 & 12 \\
Canola & 0.1 & 5 & $\ldots$ & $\ldots$ & 2.8 & 6 \\
Total & 2.8 & 100 & 39.9 & 100 & 44.2 & 100 \\
\hline
\end{tabular}

Fuente: James, 2000. 
El algodón es un cultivo de importancia entre los transgénicos: entre 1999 y 2000 aumentó en 1.6 millones de hectáreas (43\%). De los 34 millones de hectáreas cultivadas con algodón en el mundo, $16 \%$ corresponden al transgénico. Los aumentos observados se deben principalmente a mayores plantaciones en Estados Unidos (55\% y 72\% en 1999 y 2000, respectivamente). China también aumentó sus plantaciones, pero modestamente (10\%); le siguieron México, Australia, Argentina y Sudáfrica.

China fue uno de los primeros países en producir cultivos transgénicos. Comenzó en 1992 y esta actividad ha llegado a ser importante en el país. En 1999 se sembraron unas 750 mil hectáreas de tales cultivos, principalmente algodón, y se estima que en 2000 se habría llegado a 1.2 millones de hectáreas.

En Europa la situación es diferente. Las plantaciones transgénicas son de pequeña escala. España es importador de transgénicos, principalmente de maíz modificado; posee las mayores plantaciones experimentales de productos genéticos dentro de Europa, cuenta con más de 20 plantaciones experimentales y en 1999 fue el primer productor de maíz modificado, dedicando a él 10 mil hectáreas (un $0.02 \%$ de la superficie mundial). En 2000 las superficies plantadas disminuyeron en Europa, pero se sumaron dos productores, Rumania con soja y papas, y Bulgaria con maíz.

En los últimos años, la Unión Europea ha aprobado pocas plantaciones experimentales, y sólo para un número limitado de cultivos transgénicos. Lo reducido del número de autorizaciones otorgadas en la UE, frente a las concedidas en Estados Unidos, Canadá y algunos países de América Latina, está tensando a las autoridades europeas. En 1999, Estados Unidos aprobó 35 cultivos modificados, los países comunitarios sólo nueve y Japón siete.

Al comenzar 2001, el Parlamento Europeo aprobó la unificación de las diferentes normativas y autorizó la concesión de plazos y etiquetado, lo que lleva a suponer que terminará la moratoria de la comercialización de productos agrícolas modificados. Esta nueva actitud puede comenzar a acercar las posiciones de los países europeos con la de Estados Unidos.

\section{Producción en América Latina}

La superficie con cultivos transgénicos en los países en desarrollo aumentó 14\% en 1997, $18 \%$ en 1999 y $24 \%$ en 2000. En este último año una cuarta parte de la superficie mundial plantada con estos cultivos correspondió a países en desarrollo (10.7 millones de hectáreas).
Entre 1999 y 2000, los cultivos transgénicos en los países en desarrollo aumentaron de 7.1 a 10.7 millones de hectáreas $(51 \%)$ y los países que más colaboraron a este incremento fueron China y Argentina, el primero con 0.5 millones de hectáreas y el segundo con 10 millones.

En 1998 se destacaron dos productores de cultivos transgénicos: Argentina con $15 \%$ del área total y México con cerca del 1\%. Argentina cuenta con la mayor superficie de cultivos transgénicos en América Latina y es el segundo productor de ellos a nivel mundial. En 1998, dedicaba 4.3 millones de hectáreas de un total de 28 millones a nivel mundial.

La soja ocupa la mayor cantidad de hectáreas entre los cultivos transgénicos y Argentina es el tercer productor mundial de ella. En los últimos cinco años se elevó en $29 \%$ la superficie dedicada a este cultivo transgénico y en los últimos diez años se duplicó, alcanzando en 2000 a 7.4 millones de hectáreas. De los 4.2 millones de hectáreas sumadas ese año al cultivo mundial de soja transgénica, 2.7 millones correspondieron a Argentina y 1.5 millones a Estados Unidos; en 2000, el área total cubierta con soja fue de 9.6 millones de hectáreas en Argentina y de 30.2 millones en Estados Unidos.

Por su parte, el cultivo de maíz modificado mostró en Argentina un aumento de 5\% a 20\% entre 1999 y 2000, que junto al exhibido por Sudáfrica compensó parcialmente una caída en Estados Unidos y Canadá.

México posee uno de los niveles más altos del mundo en biodiversidad y su protección es prioritaria. Ha autorizado unas 150 solicitudes de liberación de organismos genéticos en campos, invernaderos y laboratorios, unas 33 en maíz, 28 en algodón, 15 en tomate, 13 en soja y 3 en trigo, entre otras.

En Brasil, la biotecnología se aplica especialmente en la agricultura. Este país es el segundo productor mundial de soja, con un rendimiento de 30.5 millones de toneladas en el período 1998-1999. Cuenta con una gran diversidad biológica y el gobierno la protege limitando y prohibiendo los cultivos modificados hasta que se efectúen estudios de impacto ambiental. A fines de 2000 la posición pareció revertirse ante el anuncio del Ministro de Agricultura de permitir la producción de aquellos cultivos de los cuales existe demanda.

En Chile hay cerca de 5000 hectáreas de cultivos de semillas transgénicas manejadas principalmente por empresas extranjeras. Existe oferta de tierras para su reproducción y la posibilidad de aumentar las exportaciones de semillas en otra temporada. El país importa semillas de maíz, soja, remolacha, canola y 
tomate desde 1992, permitiéndose sólo reproducir y exportar las semillas, pues el comercio aún no es permitido (Manzur, 1999). No autoriza la producción de alimentos transgénicos para consumo local, pero los importa, desconociendo el origen de los insumos incorporados. Un alto porcentaje de las importaciones de alimentos con componentes de soja y maíz proviene de Argentina y Estados Unidos, sin que se advierta la incorporación de genes manipulados.

En Uruguay y Paraguay prevalece una posición cautelosa. En 2001, el Ministro de Ganadería, Agricultura y Pesca de Uruguay autorizó siembras experimentales, pero no la venta. En Paraguay está pendiente una solicitud para autorizar a Argentina y a Estados Unidos a que introduzcan semillas transgénicas de soja y maíz, pero hasta el momento el país está considerado libre de transgénicos (The Biotechnology Knowledge Center, 1999a, 1999b).

Costa Rica, con una rica diversidad biológica, utiliza herramientas biotecnológicas para conservarla. Se estima que tiene el 5\% de la biodiversidad existente en el mundo (Brañes y Rey, 1999). El uso de pesticidas agrícolas se triplicó entre 1993 y 1996 en cultivos de plátanos, café y arroz, provocando problemas de salud laboral y de contaminación de tierras, agua y animales.

\section{El comercio}

Entre 1995 y 1998, las ventas mundiales de cosechas transgénicas se elevaron notablemente de 84 millones de dólares a cerca de 2300 millones. En 1999 fueron de 3000 millones de dólares (Krattiger, 1999), estimándose que llegarán a unos 20000 millones en 2010 (James, 1999). El mercado más importante es el de las semillas, seguido por los insumos agrícolas microbiológicos y el creciente comercio de nuevos vegetales y frutas comercializados directamente por las empresas que los desarrollan (Jaffé e Infante, 1996).

Algunas autorizaciones para comercializar productos transgénicos se refieren a la soja, la canola, el algodón y la papa. Los países que más comercializan alimentos modificados son Estados Unidos, Canadá y Australia y países latinoamericanos como Argentina y México. En Europa, la comercialización comenzó lentamente, permitiéndose sólo la de 18 productos transgénicos entre 1992 y 1998.
Estados Unidos lidera el uso de la ingeniería genética en la producción modificada exportable de soja, maíz, trigo y algodón. Bordea el $90 \%$ del comercio mundial de soja y maíz transgénicos. Sólo en soja transgénica exporta un $40 \%$ a Europa. En soja modificada y no modificada exportó unos 9 millones de toneladas en 1998 (The Economist, 1999).

Las exportaciones estadounidenses de maíz modificado a la Unión Europea disminuyeron de 2.7 millones de toneladas a 100 mil entre 1995/96 y 1997/98, resultado de la desconfianza de los consumidores de la UE ante sus posibles efectos en la salud.

Japón es importador de alimentos transgénicos, principalmente procedentes de Estados Unidos. Actualmente importa 29 variedades de siete cultivos: maíz, soja, colza, papa, algodón, tomate y remolacha (Programa Chile Sustentable, 1999).

El libre intercambio se ve amenazado por regulaciones nacionales como el control de la producción y de la importación, limitaciones de acceso o venta, o prohibiciones directas a la entrada a los mercados. Está latente el peligro de que surjan regulaciones de seguridad alimentaria ante la presión de los consumidores y defensores del medio ambiente.

El aumento de los opositores al consumo de alimentos transgénicos ha afectado los destinos de las exportaciones de soja de Argentina. En 1999, el 40\% de estas semillas y alrededor del $60 \%$ de las píldoras de soja fueron a Europa; luego, se dirigieron a países donde los consumidores no se oponen a este consumo, como India, China y algunos países latinoamericanos.

Otros países de América Latina han manifestado el deseo de contar con líneas definidas que guíen el comercio de los alimentos obtenidos por aplicaciones biogenéticas, pues están conscientes de que cuentan con un activo, la biodiversidad, que desean conservar. Y, por lo demás, son productores de variados productos orgánicos (verduras y hortalizas) con mayores perspectivas de aceptación que los transgénicos.

No se prevé detener la producción y comercialización de alimentos transgénicos. Al contrario, a corto plazo ingresarán al mercado algunos nuevos, ahora con vacunas incorporadas. Esto puede poner en peligro los ingresos de divisas por exportaciones de alimentos tradicionales si los países en desarrollo, y entre ellos algunos latinoamericanos, sustituyen productos por otros con características similares pero obtenidos con tecnología in vitro mediante organismos transgénicos. 


\section{III}

\section{Protocolo de bioseguridad y normas de la omc}

\section{El Protocolo de Bioseguridad}

\section{a) Antecedentes}

La aplicación de la biotecnología en cultivos y alimentos agrícolas generó desde un comienzo un debate sobre su impacto en la agricultura, el medio ambiente y la salud humana. Así, no es extraño que los temas científicos, socioeconómicos y medioambientales relacionados con los recursos biológicos y biotecnológicos aparezcan frecuentemente en los principales foros de negociación.

Las preocupaciones ambientales se manifestaron en la Cumbre de la Tierra (Rio de Janeiro, 1992) y se concretaron en la Declaración de Rio sobre el Medio Ambiente y el Desarrollo, en la Agenda 21 y en el Convenio de Diversidad Biológica (CDB). Las negociaciones del Protocolo de Biodiversidad comenzaron en 1996 y se han realizado seis reuniones, la primera en Aarthus, Dinamarca, y la última en febrero del 2000 en Montreal, Canadá.

El CDB establece que los países deben considerar las modalidades y la necesidad de un Protocolo que regule los procedimientos en materia de transferencia, manejo y uso de los organismos transgénicos con efectos adversos en la biodiversidad y en sus componentes. Se buscó crear así un marco jurídico internacional para aplicar medidas de seguridad o de mínimo riesgo para que este avance tecnológico no afecte la biodiversidad, hoy amenazada por una sobreexplotación de los recursos y degradación de los ecosistemas, con el riesgo de homogeneizar los cultivos.

Los países de la Unión Europea definieron las normativas, las leyes internas y las de la UE relacionadas con la salud humana y el medio ambiente. Incluyeron regulaciones sobre la producción agrícola, y dentro de ella sobre los alimentos transgénicos, dirigida a fines experimentales o de comercialización, para evitar repercusiones negativas en ellos mismos y en otros Estados.

Por otra parte, la dificultad de armonizar los distintos intereses nacionales, aparte la adhesión al CDB, hizo que la biodiversidad dejara de ser un patrimonio común de la humanidad y pasara a ser un patrimonio de los Estados, asignándose a éstos la responsabilidad de preservarlo. Como resultado, se determinó que los
Estados tenían también responsabilidades territoriales en la reglamentación de sus normas internas.

En 1999, los ministros de medio ambiente de la UE intentaron frenar la expansión de los organismos transgénicos y aprobaron una "declaración política" reconocida como una moratoria de facto para suspender nuevos cultivos y autorizaciones de comercialización, la que regirá hasta que las investigaciones sean más concluyentes. La decisión plantea conflictos con los Estados Unidos y con empresas productoras de alimentos transgénicos y podría generar quejas ante la omc.

$\mathrm{Al}$ incluir el principio de precaución en el Protocolo, la Unión Europea puede bloquear la siembra de semillas con genes incorporados o prohibir su importación, aduciendo dudas o insuficiente información. Los ministros de Francia, Grecia, Italia, Dinamarca y Luxemburgo defienden la moratoria a la introducción de nuevos cultivos. Países con una posición más favorable a la comercialización son Alemania, España, los Países Bajos y el Reino Unido. De ellos, Alemania y España, que cuentan con un incipiente mercado, no se opusieron a la moratoria. Por otra parte, algunos países no quieren distanciarse de negocios asociados a las principales comercializadoras biotecnológicas, ni tampoco enfrentar posibles sanciones de la OMC.

En los Estados Unidos, para introducir un alimento agrícola transgénico al mercado debe cumplirse con procedimientos establecidos por tres agencias federales: el Departamento de Agricultura de los Estados Unidos, la Administración de Alimentación y Drogas y la Agencia de Protección Ambiental. La responsabilidad en materia de salud es del Instituto Nacional de la Salud y de una división del Departamento de Agricultura que fiscaliza la seguridad alimentaria.

Algunos de los países en desarrollo están en favor de reglamentar el comercio de alimentos transgénicos, aduciendo que se desconocen sus efectos sobre la salud y el medio ambiente. Les preocupa que en el futuro se sume la dependencia de la biotecnología importada al alto grado de subordinación a los conocimientos científicos externos y manejo de nueva tecnología. La aceptación de una ley internacional que regule el comercio transfronterizo puede impedir que sus tierras sirvan de campo de experimentación con estos cultivos, evitando así posibles riesgos ambientales. 
b) Posiciones y negociaciones en el debate El proceso negociador en Cartagena y en Montreal fue difícil y los países que sustentaron posiciones más contrapuestas tuvieron que ceder en sus exigencias, para poder aprobar el Protocolo de Bioseguridad. Las discusiones fueron llevadas a otros foros internacionales, donde participaron diferentes actores, incluidos representantes de consumidores y ambientalistas.

La biotecnología ha elevado el valor de los recursos genéticos e hizo aconsejable promulgar marcos reguladores internacionales. El Convenio de la Diversidad Biológica llamó a los Estados analizar las modalidades de un instrumento internacional regulador del uso de las nuevas técnicas. El Protocolo de Bioseguridad, instrumento internacional, suscribe sólo el movimiento transfronterizo de los productos y pide a sus Estados miembros complementarlo con legislaciones nacionales.

Las dificultades para lograr un consenso llevaron a los países a agruparse según sus intereses y opiniones. Se formaron cinco grupos negociadores: i) el Grupo Miami, integrado por los Estados Unidos, Canadá, Australia, Argentina, Uruguay y Chile; ii) los países de la Unión Europea; iii) el Grupo de Avenencia; iv) países de alto nivel de biodiversidad, como Suiza, Noruega, Nueva Zelandia, México, Japón y la República de Corea, y v) países con ideas afines, integrado por países en desarrollo como China y países de Africa, Asia, América Latina y el Caribe, excepto los ya mencionados.

Las negociaciones comenzaron con temas relativos a la biodiversidad y condiciones de seguridad en la salud humana y medio ambiente. Continuaron con la evaluación de riesgos en el manejo, uso y transporte de los productos transgénicos, las implicaciones socioeconómicas, las responsabilidades por daños o accidentes, la capacidad institucional y el intercambio de información. Con el tiempo, se trataron aspectos relacionados con el comercio, como el movimiento transfronterizo, el principio de precaución, el etiquetado, y la relación con otros acuerdos internacionales, en particular con la omc en los Acuerdos sobre Medidas Sanitarias y Fitosanitarias (MSF) y de Barreras Técnicas al Comercio (BTC).

La postura de los países de la Unión Europea y un número de países en desarrollo relacionaba el Protocolo de Bioseguridad a los acuerdos medioambientales. Se temía dejar sin validez los controles a los alimentos transgénicos y que se impusieran medidas comerciales por sobre las ambientales y sanitarias. Los miembros buscaron equilibrar los temas medioambien- tales con los comerciales y complementar los primeros con los de la OMC.

Los países de la Unión Europea consideraban que era necesario evaluar el riesgo en el principio precautorio fundamentado científicamente. Dicho principio, no regulado en el derecho internacional, no permite que circulen alimentos sin saber con certeza que no tienen efectos adversos en la salud o el medio ambiente. Los países que se inclinan por reglas internacionales rechazan la importación de alimentos transgénicos si éstos no han aprobado el examen de evaluación de riesgos que efectúen las autoridades nacionales y de la UE. La Comisión Europea no permite prohibir unilateralmente un cultivo, a no ser que se demuestre con nueva evidencia científica que tal cultivo es dañino.

Los miembros de la Unión Europea se esforzaron por lograr una normativa y una posición común frente a los organismos modificados, viéndose obligados a reglamentar la liberación de ellos (para ventas, ensayos, comercio) en sus territorios. La mayor rigurosidad de las directrices europeas frente a la ausencia de legislaciones adecuadas en otros mercados ha llevado a sus empresas con intereses biotecnológicos a experimentar en mercados no regulados, o en los propios, bajo previa autorización. Las divergentes opiniones gubernamentales sobre los efectos que causan los distintos estándares de seguridad alimentaria nacionales dificultan el avance negociador.

En 2000, la Comisión Europea dio un giro en su posición ante el bloqueo existente desde 1998 a la autorización de nuevos productos transgénicos: hoy admite que el bloqueo es una norma ilegal e injustificada que debe levantarse y espera adoptar nuevas propuestas, pero al otorgar nuevas licencias, a mediano o largo plazo, las empresas biotecnológicas deberán aceptar normas más rigurosas que incorporen evaluaciones de riesgo, etiquetado y un control comercial más estricto.

Los países del Grupo Miami impidieron aprobar un marco regulador que obstaculizara el libre intercambio de los alimentos transgénicos y sus derivados. ${ }^{4} \mathrm{Al}$ Grupo le preocupaba que el principio precautorio pudiera utilizarse como barrera legítima al comercio cuando no se contara con una base científica sólida. El Grupo fue renuente a incluir en el Protocolo el etiquetado, elemento esencial del principio precautorio en la comercialización.

\footnotetext{
${ }^{4}$ Estados Unidos, por no haber ratificado la $\mathrm{CDB}$, no tiene derecho a voto en las negociaciones del Protocolo.
} 
La posición de los Estados Unidos es que sólo aquellos alimentos transgénicos sustancialmente diferentes a los tradicionales justifican una regulación. De lo contrario, plantea ese país, la Unión Europea podría aprovechar de exigir a todos los alimentos modificados una etiqueta que incluyese el origen genético del producto; el régimen comercial de la OMC debe prevalecer sobre el Protocolo de Bioseguridad (Kerr, 1999).

Las negociaciones para definir las reglas del comercio de los alimentos transgénicos fracasaron en la reunión de Cartagena, en 1999. Algunos países temían que las reglas de la омC entrasen en conflicto con las del Protocolo, pues percibían que el grupo ambientalista no conocía cabalmente las reglas del comercio internacional. Así, de aceptarse el Protocolo, se podría limitar el movimiento internacional de alimentos transgénicos por razones de salud humana, vegetal o animal o por daño medioambiental. Esto no debería crear barreras al comercio agrícola ni debilitar el Acuerdo MSF.

A principios de 2000, el Grupo Miami evitó que otros gobiernos exigiesen una autorización para la importación previa a la exportación. Las negociaciones se estancaron y un año después en Montreal, el Grupo Miami y la Unión Europea cedieron en sus posturas iniciales, acercándose a una posición conciliadora. 135 Estados aprobaron el Protocolo, que al ratificarse se sumará a otros tratados ambientales para regular el comercio.

\section{c) El Protocolo y su significado}

Es útil diferenciar dos casos de introducción al medio de organismos transgénicos: uno es su incorporación al cultivo (por ejemplo, semillas) y otro es la incorporación al procesamiento y al consumo humano y animal (por ejemplo, granos). Esta distinción ayudará a entender ciertos aspectos de algunos de los principios incluidos en el Protocolo.

Este establece que cada país puede adoptar sus propias regulaciones respecto de los alimentos transgénicos y que tales normas pueden ser más exigentes que las del mismo Protocolo, pero exige notificarlas a las demás naciones. Para compartir tal información se estableció un organismo: el Acuerdo Informado Previo (AIP), principal aporte y pilar del Protocolo.

El AIP es sólo un control previo a la autorización para el consumo humano en los países importadores, es decir, es una notificación entre países. Dicho acuerdo exige que el país importador conceda la autorización para realizar el primer movimiento transfronterizo del organismo transgénico. Esto permite obtener infor- mación acerca de los países que rechazan los alimentos transgénicos. Además, la aplicación del AIP permite una evaluación de los riesgos y de sus posibles efectos adversos, y si los hay, la negación del acceso, fundamentado científicamente para evitar barreras comerciales injustificadas.

El AIP permite imponer restricciones al comercio pero no al cultivo de transgénicos. A partir de 2002, las exportaciones realizadas principalmente por los Estados Unidos, Canadá y Argentina deberán obtener un permiso del país importador y notificarlo a un organismo regulador de las Naciones Unidas.

Aquí surge la primera responsabilidad del país exportador, que debe notificar su intención de exportar, y del importador, que debe desarrollar y anunciar sus regulaciones. El exportador puede optar por un sistema de regulación nacional consistente con el Protocolo o por un sistema regulado por el mismo Protocolo. El AIP permite el veto del país importador ante pruebas científicas aportadas por el país exportador (Cosbey y Burgiel, 2000).

En aquellos organismos transgénicos destinados al procesamiento y consumo no se exige el AIP. Con la evaluación de riesgo el importador puede solicitar información adicional, aceptar el acceso con o sin condiciones, prohibir la entrada o prorrogar el plazo de ingreso del organismo modificado. Aun cuando el AIP no cubre los productos agroindustriales con procesos productivos que hayan incluido algún organismo transgénico, es un antecedente de protección al consumidor y al medio ambiente por no contar con información científica sólida.

El Protocolo incluye el principio precautorio, para proteger al medio ambiente de la reducción de la biodiversidad y a resguardar la salud de los consumidores. La regulación de los movimientos transfronterizos de los alimentos agrícolas transgénicos evita riesgos ambientales y sanitarios. Otros aspectos de la bioseguridad deben cubrirse con las leyes nacionales.

El principio precautorio es una opción gubernamental para rechazar el acceso sin ser penalizado internacionalmente. Posibilita que el país reciba la información sobre uso y seguridad exigida cuando se introduce el organismo transgénico en el medio, y requiere notificación entre los países al aplicar el AIP. Permite imponer restricciones y garantías al comercio de transgénicos por insuficiente información científica y estima la presencia de riesgo para la biodiversidad o la salud humana.

El principio precautorio se alcanzó por el apoyo mutuo entre los instrumentos ambientales y de comercio, sin subordinación de los primeros a los acuerdos 
comerciales multilaterales. La diversidad biológica y la seguridad alimentaria no prevalecen sobre las normas de la OMC y viceversa. El Protocolo de Cartagena se basa en el principio precautorio y la OMC en la evidencia científica.

El Protocolo no debe afectar los derechos y obligaciones de los gobiernos bajo otros acuerdos internacionales (de la omc o cualquier otro). En lo comercial, no implica un cambio en los derechos y obligaciones pactados bajo un acuerdo internacional, incluidos los Acuerdos MSF y BTC. Los controles permitidos al comercio de productos transgénicos bajo el principio precautorio invierten la carga de la prueba, es decir, el introducir mayores controles si no hay evidencia científica cierta de ausencia de riesgo

Al comenzar una actividad debe demostrarse que su resultado es inocuo para el medio ambiente; de lo contrario, sus efectos son controlados y pueden inducir al país a imponer estándares más altos que los establecidos en otros acuerdos internacionales, como derecho del Estado. La Comisión Europea considera que cada miembro de la omc tiene derecho a establecer el nivel de protección que estime apropiado, particularmente en lo que se refiere al medio ambiente y la salud humana. Pero Estados Unidos rechaza que el principio precautorio de la Unión Europea sea aceptado como una barrera legítima al comercio. Argumenta que debe resolverse apelando a la ciencia, que hoy no puede responder con certeza que los productos transgénicos serán seguros a futuro.

\section{Las normas de la омс}

Es función de la OMC resolver las controversias comerciales entre sus miembros. Respecto a la seguridad de los alimentos modificados, ofrece principios a los que se puede recurrir cuando los países se enfrentan a divergentes interpretaciones de cómo proteger a los consumidores.

Aun cuando los miembros de la OMC no le han otorgado un mandato para desarrollar estándares de seguridad alimentaria, sí cuenta con normas para evitar que los miembros utilicen barreras comerciales innecesarias y sin justificación. Esas normativas se enmarcan en los Acuerdos sobre MSF, BTC y Propiedad Intelectual relacionados con el comercio, y en las excepciones del GATT, artículo XX b) y g). ${ }^{5}$

\footnotetext{
${ }^{5}$ Permite a los gobiernos adoptar medidas comerciales necesarias para proteger la salud humana y animal, y preservar los vegetales y la seguridad de los recursos naturales agotables.
}

El país tiene derecho a establecer sus propias normas ambientales y de seguridad alimentaria de acuerdo con el artículo XX del GATT. Pero este derecho debe ser consistente con los principios de la omc: ausencia de discriminación entre las naciones y trato nacional una vez que la importación entra al mercado nacional. Sin embargo, ante la presencia de un producto biotecnológico algunos actores argumentan que el proceso productivo es un elemento relevante. Si las reglas del comercio incluyeran a los procesos productivos usando las excepciones del artículo XX del GATT, su justificación debería probarse científicamente, de lo contrario se necesitaría una modificación al artículo (CEPAL, 1998).

No existe en la omc un compromiso que regule el comercio de los productos transgénicos, ni tampoco normas internacionales que rijan su intercambio según el método de producción. Las reglas del comercio internacional dirigen su atención al comercio de productos y no al proceso productivo, salvo que éste afecte la seguridad y ponga en peligro el recurso natural, la salud humana y la animal.

Existen argumentos a favor y en contra de la conveniencia de modificar el artículo XX del GATT para permitir la aplicación de medidas comerciales a los procesos productivos. Es un punto que habrá que discutir y resolver en futuras negociaciones, como también habrá que definir si el Protocolo debe incluir sólo a los microorganismos transgénicos o también a los procesos productivos que en alguna parte de la cadena productiva utilizaron técnicas biotecnológicas.

Las regulaciones nacionales pueden conducir a las partes a discrepar. Aquellos países que consideran que un producto obtenido por métodos productivos tradicionales y uno obtenido a través de la biotecnología son similares, insisten en que los acuerdos de la OMC son los adecuados para resolver las diferencias. Por el contrario, aquellos que consideran que son productos diferentes porque su proceso productivo es distinto, aducen una falta de regulación en el comercio de productos biotecnológicos.

La idea de anexar el Protocolo a los acuerdos de la omc fue defendida por el Grupo Miami, que respeta los acuerdos de esta organización. Propone que las divergencias sobre el comercio de los productos transgénicos sean regladas al interior de la OMC y no por acuerdos particulares. Este tema está inscrito para discusión en la próxima ronda de negociaciones de la organización (омC, 1999).

Otros países recurren al principio precautorio como manera de justificar medidas proteccionistas. La 
Unión Europea ha pedido a la OMC que clarifique el uso de dicho principio y que extienda su aplicación al marco de la organización. Argumentan que los productos transgénicos constituyen una tecnología nueva que justifica el uso del principio, pues la prevención de potenciales riesgos y la preservación del medio ambiente deben estar por sobre la liberalización del comercio. Los cultivos con genes incorporados son vistos por los miembros de la UE como fuente de riesgos potenciales.

Hasta ahora, la OMC ha condenado la prohibición de la Unión Europea de importar carne tratada con hormonas, el embargo australiano del salmón del Pacífico y los requisitos de Japón de someter a pruebas una variedad de frutas, por no existir evidencia científica que garantice la inocuidad de su consumo. Ambos - la evidencia científica sólida y en su ausencia el principio precautorio- provocan tensión en las negociaciones comerciales.

Nuevas restricciones al intercambio pueden causar fricciones con el sistema multilateral de comercio. Según la OMC, los Acuerdos MSF y BTC proveen los lineamientos para negociar las regulaciones comerciales y el etiquetado; sin embargo, al firmarse estos acuerdos en 1994 el tema de los productos transgénicos no estaba en negociación. Ambos acuerdos aspiran a regular las restricciones comerciales al uso indiscriminado de medidas técnicas como salvaguardias de la salud humana, el medio ambiente y los intereses nacionales, así como a armonizar las normas alimentarias nacionales.

\section{a) Acuerdo sobre Medidas Sanitarias y Fitosani- tarias}

Este Acuerdo MSF suscrito en la Ronda Uruguay regula la aplicación de las medidas sanitarias y fitosanitarias. Se aplica a todas las medidas que puedan afectar directa e indirectamente al comercio internacional y que sean consideradas necesarias para proteger la salud humana. Se refiere a las reglamentaciones en materia de inocuidad de los alimentos, y permite a los gobiernos imponer medidas internas e internacionales temporales, si no están asegurados la inocuidad del alimento y el control sanitario de animales y vegetales.

El Acuerdo MSF permite a los gobiernos regular el comercio aplicando medidas nacionales más estrictas que la norma internacional. Para hacerlo se debe demostrar científicamente que la norma internacional ofrece menor protección sanitaria y proceder a una evaluación del riesgo; de lo contrario, puede generarse una proliferación de medidas sanitarias y fitosanitarias que impidan el flujo comercial (oMc, 1996).

Hay diferencias importantes entre el Acuerdo MSF y el Protocolo de Bioseguridad. Una se refiere al riesgo. El Acuerdo señala que existe un nivel de riesgo, pero no estipula qué constituye riesgo; promueve evaluaciones de riesgo sistemáticas pero no menciona cómo administrarlas; para aplicar el nivel adecuado de riesgo los gobiernos revisan casos similares en otros países. En cambio, el Protocolo indica qué es un riesgo, cómo evaluarlo, cómo administrarlo y, de no contar con una base científica, permite utilizar el principio precautorio para prohibir o restringir una importación.

El Acuerdo MSF permite adoptar medidas provisionales cuando la evidencia científica es insuficiente, en tanto que el principio precautorio es relativamente más restrictivo para los consumidores. El Protocolo permite al importador requerir al exportador que realice una evaluación de riesgo para tomar decisiones; en cambio, el Acuerdo determina previamente qué constituye riesgo y cómo calcularlo (Cosbey y Burgiel, 2000).

Con nueva información científica, el Protocolo permite al importador revisar y modificar una decisión sobre el movimiento transfronterizo de los productos transgénicos, en tanto que las medidas del Acuerdo MSF son más ambiguas. En el marco de la OMC, la normativa no juzga si existe una evidencia científica apropiada o cuál es la mejor evidencia frente a un alimento transgénico. Sin embargo, a pedido de la misma OMC esta función ha sido traspasada a la Comisión del Codex Alimentarius, que busca elaborar una norma general sobre la inocuidad de los alimentos, controlar los alimentos biotecnológicos y desarrollar estándares alimentarios internacionales voluntarios que han de ser sometidos a los gobiernos para su aceptación e utilización al aplicar los Acuerdos MSF y BTC.

Las normas que elabora la Comisión del Codex Alimentarius deben permitir juzgar si las normas nacionales entorpecen el flujo del comercio internacional. Si las regulaciones nacionales no están debidamente justificadas frente a la norma internacional del Codex, el conflicto debe juzgarse en la omc.

b) Acuerdo sobre Barreras Técnicas al Comercio El Acuerdo BTC incorpora las normas técnicas de los estándares y regulaciones nacionales, regula los requisitos de calidad alimenticia y las obligaciones no cubiertas por el Acuerdo msF e incluye prescripciones 
técnicas resultantes de medidas en materia de inocuidad de los alimentos, de inspección y de etiquetado.

Por los derechos y obligaciones estipulados en el Acuerdo BTC, los países pueden imponer normas técnicas con una intención legítima, siempre que los requisitos exigidos no constituyan barreras más restrictivas al intercambio transfronterizo que las necesarias para cumplir con los objetivos. Un aporte del Acuerdo es proporcionar los principios internacionales para eliminar barreras comerciales infundadas, evitar que se creen nuevos obstáculos, contar con elementos para desarrollar estándares internacionales y posibilitar que los estándares nacionales se lleven a niveles internacionales.

El Acuerdo no proporciona una definición clara y precisa del significado de los estándares internacionales de los alimentos transgénicos y tampoco se cuenta con una distribución equitativa de las necesidades nacionales. La escasa información disponible hace que los estándares reflejen las disposiciones de algunos países. El Protocolo de Bioseguridad debe precisar una definición de los estándares en el ámbito nacional y en el internacional.

La Comisión del Codex Alimentarius está considerando si adopta un estándar internacional de etiquetado de los alimentos transgénicos basado en una equivalencia sustancial. Se necesita definir si el organismo transgénico es sustancialmente equivalente a un alimento original. El etiquetado buscaría asegurar que los estándares elegidos apoyen al consumidor en su derecho a informarse y elegir, a reconocer el contenido del alimento y a distinguir los insumos utilizados en el proceso productivo. No obstante, esto exigiría no perder de vista el ciclo de vida del alimento, tarea nada de fácil. Y aun pudiendo seguir cada etapa del proceso, no todos los países estarían en condiciones de cumplir con tal exigencia.

La FDA de los Estados Unidos no prevé un etiquetado especial y argumenta que, no teniendo certeza científica que demuestre que el consumo de un producto transgénico altera la composición del alimento y daña la salud, la etiqueta deja de ser obligatoria. No rechaza la etiqueta voluntaria, pero no pretende establecer una distinción obligatoria entre un alimento transgénico y uno original, si no existe una diferencia sustancial. En algunos países han surgido problemas comerciales por presiones internas para usar las etiquetas como condición de acceso al mercado.

El Protocolo no contempla separar físicamente los productos modificados genéticamente de los demás.
Las divergencias sobre el etiquetado se han solucionado parcialmente, al ceder los Estados Unidos a la presión de la Unión Europea para que el etiquetado sea obligatorio. Este es sólo un punto de partida para conciliar intereses y comenzar una nueva etapa negociadora. La obligación de etiquetar es también una preocupación que comparten Brasil y Argentina. El gobierno de Canadá está evaluando si debe introducir nuevas regulaciones al respecto, pues su posición es similar a la de los Estados Unidos. En Japón, el etiquetado es obligatorio desde abril de 2000.

La Comisión Europea no considera necesario un etiquetado especial, pero el Parlamento Europeo sí exige información completa para diferenciar los productos y cree necesario tomar medidas más drásticas en la regulación de los cultivos transgénicos. En algunos países de la Unión Europea la prioridad se centra en la biotecnología, en la introducción de nuevos alimentos transgénicos al mercado, en el almacenamiento y caducidad de los productos, o en la responsabilidad frente a la seguridad alimentaria.

Las principales exportaciones de alimentos transgénicos desde los Estados Unidos a países de la UE son trigo, algodón y soja, justamente los que originan divergencias. Para los Estados Unidos, estos alimentos no presentan riesgos para la salud. Sin embargo, algunas empresas europeas han dejado de utilizarlos como insumos en sus procesos productivos, por temor a incorporar organismos modificados.

Los ambientalistas europeos continúan temiendo que a largo plazo surjan efectos medioambientales negativos. Argumentan que se priva al consumidor de acceder a la información sobre potenciales peligros y opinan que los gobiernos debieran exigir el etiquetado de todos los alimentos transgénicos. Manifiestan que el rechazo de algunas industrias biotecnológicas a aceptar la etiqueta obligatoria demuestra desconfianza en su propia producción.

En general, la legislación nacional e internacional sobre el control de los organismos transgénicos es aún escasa. En muchos países desarrollados las exigencias al gobierno por parte de grupos consumidores y organizaciones no gubernamentales de que haya un control efectivo y seguro de la oferta alimentaria son mayores que en los países en desarrollo. Al respecto hay propuestas de establecer un organismo gubernamental con capacidad técnica y económica de revisar la importación de alimentos y verificar la veracidad de la información contenida en el envase. 


\section{V}

\section{Consideraciones finales}

La moderna biotecnología debe verse como un complemento y no como un sustituto de las técnicas agrícolas tradicionales. Su empleo necesita de la intervención del hombre para mover los genes entre distintas especies. La incertidumbre frente al consumo de un alimento transgénico o de uno híbrido — que también resulta de modificaciones genéticas pero dentro de una misma especie - cuestiona al primero y no al segundo.

La biotecnología es sólo una herramienta para solucionar algunos problemas vinculados con la agricultura. Inquietan a la sociedad sus posibles riesgos ambientales, sanitarios y socioeconómicos. Los riesgos para la salud humana son más comunes y similares entre los países, pero los ambientales deben estudiarse caso a caso pues varían los efectos, positivos y negativos, de aplicar las nuevas herramientas.

Estas técnicas ofrecen posibles soluciones a problemas actuales, como los de desarrollar la agricultura y la industria alimentaria y satisfacer las necesidades nutricionales de una creciente población. En parte esto puede lograrse si prospera una nueva generación de alimentos que incorpore nuevas características y genere ventajas frente a alimentos tradicionales similares.

Para que se pueda determinar si es beneficioso o no comercializar un alimento transgénico es preciso entregar mayor información al público sobre las ventajas y seguridad biológica de su consumo. Una participación activa del consumidor en los debates y su asesoramiento con información a su alcance disminuirían la incertidumbre. Pero la falta de financiamiento para poner en marcha las necesarias redes informáticas dificulta el proceso de comunicación, especialmente en los países en desarrollo.

La ausencia de reglas sobre los alimentos biotecnológicos en el comercio internacional desencadenó una serie de rondas negociadoras que finalizaron cuando cedieron los países con posiciones opuestas. La aprobación del Protocolo demostró que, al ceder las partes, se equilibraron los intereses del comercio con las preocupaciones del medio ambiente.

El Protocolo exige legislar internamente, desarrollar un marco jurídico de aplicación biotecnológica, evaluar los riesgos de adaptación, determinar el nivel de protección deseado y contar con instituciones na- cionales preparadas para llevar a cabo las tareas pertinentes. Pero el desarrollo dinámico de la ciencia, las normativas y regulaciones nacionales establecidas y el nivel de riesgo incorporado impulsa a las instituciones a gestar nuevas regulaciones y a efectuar continuas revisiones, complementando y ampliando reglas que den seguridad al consumidor.

Los países en desarrollo deben contar, además, con la capacidad de adaptar, implementar, difundir e innovar en un sector que es accesible, pero de alta tecnología. Por lo tanto, necesitan instituciones de investigación que, además de cumplir con su propio objetivo, tengan la función de unir a los inversionistas y creadores de tecnologías con los consumidores.

El desarrollo biotecnológico beneficia a los productores, otorga gratificación directa a los consumidores y reconoce los beneficios y riesgos que puede aportar al sector agrícola. Pero para lograr la seguridad alimentaria es recomendable que los países en desarrollo, y en éstos particularmente los agricultores de escasos recursos, se beneficien más de los avances de la biotecnología, tengan más acceso a las fuentes de recursos genéticos y a la financiación pública y puedan recoger los frutos de un diálogo aventajado entre los sectores públicos y privados (FAO, 2000).

La confianza de los consumidores en las instituciones que recomiendan las normas es cada vez más importante en las decisiones que ellos tomen. La falta de transparencia y claridad de las normativas y la demora en tomar medidas apropiadas en respuesta al problema emergente son elementos en contra.

Preocupan las diferentes visiones frente a los productos transgénicos. Para los Estados Unidos, sólo puede ser tema de regulación el producto final y no el proceso productivo; en cambio, para la Unión Europea tanto el producto final como el proceso productivo están sujetos a regulación. La tendencia a regular el proceso productivo genera polémica, pues esta norma no es aceptada por la omc.

Los Acuerdos MSF y вTC proveen los lineamientos para que los países orienten sus regulaciones por la ciencia y solucionen sus diferencias bilateralmente, evitando llegar a la OMC. También permiten armonizar los distintos sistemas reguladores nacionales y las exigencias de etiquetado. Pero no proponen una solu- 
ción si el conflicto se presenta por consideraciones éticas, sin una evidencia científica que justifique exigir la etiqueta. Esto puede hacer que ambos acuerdos sean objeto de revisión y de futuras negociaciones en la OMC.

La aprobación del Protocolo no elimina la posibilidad de futuros problemas, pero indica que los argumentos a favor y en contra del uso de las nuevas técnicas comienzan tímidamente a conciliarse. Hay pasos hacia una convergencia entre las distintas posiciones que, por un lado, proponen ofrecer una alimentación más abundante y, por otro, reclaman el desconocimiento de los efectos del consumo transgénico en la salud y el medio ambiente. Pero esto no significa que finalice el debate. Más bien, algunos países consideran que el Protocolo es insuficiente y desean continuar investigando para llegar a un comercio biotecnológico más seguro.

El tema de los nuevos productos agrícolas es debatido en foros internacionales y aparece recurrentemente en las negociaciones. Las controversias comerciales sobre el etiquetado y las diferentes regulaciones nacionales no disminuyen la incertidumbre. La etiqueta no informa qué genes se incluyen en la producción; la incertidumbre acerca de riesgos en el consumo posiblemente continuará y deberá negociarse qué información es pertinente incluir para lograr más transparen- cia. La inseguridad en el consumo podría paliarse si el mensaje es preciso, libre de manipulación, simple y equilibrado.

Contribuye a alimentar el debate el hecho de que los países de América Latina son poseedores de una gran biodiversidad, que es fuente de ganancias que son recogidas principalmente por las empresas trasnacionales, sin que los países de la región reciban la proporción que les corresponde por el acceso a los insumos genéticos. La cuestión del reparto de las ganancias no está resuelta y no parece fácil que se resuelva a corto plazo. En los argumentos suelen destacarse más las preocupaciones de los países que hacen mayor uso de las biotecnologías y olvidarse de las inquietudes e intereses de los países en desarrollo.

Por último, no puede concluirse a priori que un alimento, por ser transgénico, deba clasificarse como perjudicial o ventajoso, bueno o malo, dañino o inocuo. Cada nuevo alimento deberá ser analizado con rigor antes de que se le lance al mercado. Es fundamental que los beneficios y riesgos de cada uno de los organismos transgénicos incorporados y sus repercusiones en los ecosistemas nacionales sean evaluados fríamente y las conclusiones transmitidas a la sociedad. Esto pavimentará el camino para avanzar en la creación de alimentos transgénicos sanos y amigables con el medio ambiente.

Bibliografía

Brañes, R. y O. Rey (1999): Política, derecho y administración de la bioseguridad en América Latina y el Caribe, México, D.F. Comisión Económica para América Latina y el Caribe (CEPAL)/Programa de las Naciones Unidas para el Medio Ambiente (PNUMA)/Asociación Latinoamericana de Derecho Ambiental, diciembre.

CEPAL (1998): Comercio y medio ambiente en la Organización Mundial del Comercio, Santiago de Chile, 31 de enero.

Cosbey, A. y S. Burgiel (2000): The Cartagena Protocol on Biosafety: An Analysis of Results, IISD briefing note, Winnipeg, Canada, International Institute for Sustainable Development (IISD). http://iisd.ca

FAO (Organización de las Naciones Unidas para la Agricultura y la Alimentación) (2000): Declaración de la FAO sobre biotecnología, Roma.

Grace, E. (1997): La biotecnología al desnudo. Promesas y realidades, Barcelona, España, Editorial Anagrama.

Harvard University, Center for International Development (1999): International Conference on Biotechnology in the Global Economy, Cambridge, Massachusetts, septiembre.

Jaffé Carbonell, W. y D. Infante (1996): Oportunidades y desafíos de la biotecnología para la agricultura y agroindustria de América Latina y el Caribe, Washington D.C., Banco Interamericano de Desarrollo (BID), septiembre.

James, C. (1998): Global Status and Distribution of Commercial Transgenic Crops in 1997, Briefs, N 35, International Service for the Acquisition of Agri-Biotech Applications (ISAAA), www.isaaa.org

(1999): Global Review of Commercialized Transgenic Crops: 1998 , Briefs, $\mathrm{N}^{\circ} 8$, ISAAA. www.isaaa.org

(2000): Global Status of Commercialized Transgenic Crops: 2000 , Briefs, $\mathrm{N}^{\circ} 21$, ISAAA. www.isaaa.org

Kerr, W. (1999): International trade in transgenic food products: A new focus for agricultural trade disputes, The World Economy, vol. 22, $\mathrm{N}^{\circ}$ 2, Oxford, Reino Unido, Blackwell Publishers, marzo.

Krattiger, A. (1999): Building public/private agri-biotech networks for resource poor farmers in Southeast Asia and Africa, ISAAA Biennal Report 1997-1999. New Partnerships for Prosperit, Nueva York, ISAAA.

Manzur, M. I. (1999): Biotecnología y bioseguridad: la situación de los transgénicos en Chile, Programa Chile Sustentable, julio. www.chilesustentable.net

Programa Chile Sustentable (1999): Boletín de actualidad sobre transgénicos, $\mathrm{N}^{\circ} 1-2$, www.chilesustentable.net

OCDE (Organización de Cooperación y Desarrollo Económicos) (1999a): Frequently Asked Questions. Biotechnology and Food Safety. www.oecd.org/subject/biotect/fac.htm

(1999b): Modern biotechnology and the OCDE. Policy brief, OCDE Observer, París, junio.

OMC (Organización Mundial del Comercio) (1996): Explicación del Acuerdo de la Organización Mundial del Comercio sobre la 
aplicación de medidas sanitarias y fitosanitarias, 15 de julio. www.wto.org

(1999): Preparations for the 1999 Ministerial Conference, Documento, $\mathrm{N}^{\mathrm{o}} 220$, Ginebra, 28 de junio.

Stilwell, M. y B. Van Dyke (1999): An Activist's Handbook On Genetically Modified Organisms and the WTO, Washington, D.C. The Consumer's Choice Council. Center for International Environmental Law, julio.
The Biotechnology Knowledge Centre (1999a): Food Safety and Genetically Modified Foods, Full Report, $\mathrm{N}^{\circ} 1472$, Food Safety Authority of Ireland, 13 de mayo. www.biotechknowledge.com (1999b): Food Safety and Genetically Modified Foods, Full Report, $\mathrm{N}^{\circ}$ 1919, Food Safety Authority of Ireland, 1 de agosto. www.biotechknowledge.com

The Economist (1999): Sticky labels, Londres, The Economist Newspaper Limited, 1 al 7 de mayo. 